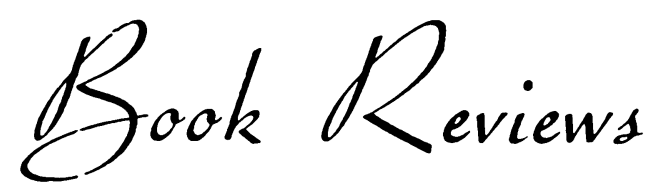

\section{SIR CHARLES BELL, HIS LIFE AND TIMES}

By Sir Gordon Gordon-Taylor, K.B.E., C.B., F.R.C.S., and E. W. WALlS, M.D., Ch.B., B.Sc., F.R.S.(Ed.). Pp. xii +288 , with 49 illustrations. Edinburgh: E. \& S. Livingstone Ltd. 1958. $42 \mathrm{~s}$.

It has been a pleasure to read and review this interesting book. Charles Bell made notable contributions to anatomy and surgery. This book gives a full account of these, and in addition, describes the medical and surgical life of London at that time. It is apparent that Sir Charles Bell's life was similar in many ways to that of one of the authors, Sir Gordon Gordon-Taylor, and this may be an added reason why the book is so well written and such a delight to read.

\section{HIGH ARTERIAL PRESSURE}

By F. H. SmiRK, M.D., F.R.C.P., F.R.A.C.P. Pp. xxxvi +764 , illustrated. Oxford: Blackwell Scientific Publications. 1957. 75s.

As would be expected from the leader in the treatment of high blood pressure with hypotensive drugs, about half of this large book is devoted to the methods and results of treatment of high blood pressure. This, I think, is the most valuable part, since all the difficulties which can be met with in such treatment are well covered. Like all enthusiasts, however, the effect on the whole patient of such treatment with ganglion-blocking drugs, tends to be regarded as wholly beneficial, whereas there are many patients whose lives have been made quite unpleasant by their use.

The rest of the book consists of a survey of all the factors known to be implicated in the aetiology of high blood pressure. It is a very valuable collection of the references in the field, but equal weight seems to have been given to good, bad and indifferent papers included in the survey, and in such a vast field what the reader needs is a critical guide.

However, over all this is a book which those who are interested in this subject ought to read. The format is good, though the way in which small subsections in the chapters are placed together at the front of the book under the chapter headings did not seem to have much point, since it acted as a second index.

\section{OUTLINE OF ORTHOPAEDICS}

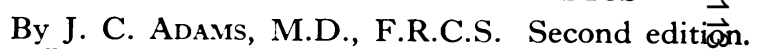
Pp. vii +428 , with 298 illustrations. EGinburgh: E. \& S. Livingstone Ltd. 1958. 35s. \&

The fact that the second edition of Mr. Adaming' book appears so soon after the first is a just tribute to its popularity. This book, intended primagyly for undergraduate students, sets out clearly the bread and butter information of orthopaedics. Epr postgraduate students and general practitioners the practical common-sense approach to orthopaegic problems serves as an example. The correlation-of clinical and radiological findings in each subject demonstrates the scope and limitation of X-roys in orthopaedics.

In this second edition the chapter on congenital dislocation of the hip has been brought up togis $\overrightarrow{g m e}$, in particular emphasizing the trend of more fre unent operation in early cases.

The length of the book is unaltered, its original purpose conscientiously adhered to. It is the book of its kind so far produced.

\section{SYSTEMIC OPHTHALMOLOGY}

Edited by ArNold Sorsby. 2nd Edition. Pp. xi韋 682 + index. London: Butterworth \& Co. I itd. 1958. £5 5s.

This book is valuable to physicians and o thalmologists, since the care taken in describtitg general conditions is nicely balanced against that taken with their ophthalmological concomitaifs. The layout and headings are excellent, the type is clear and high-quality paper is used. The contents include ophthalmological changes due to prenatal influences, inflammations, allergies, nutritional metabolic and endocrine disorders, changes in the central nervous system and the cardiovascular system and finally in a variety of other genefal disturbances, including senility and death.

There is a distinguished panel of authors, many of whom are acknowledged leaders in the subjęts they contribute, a qualification which applies pgarticularly to the author-in-chief, whose chapter $\mathbb{D}_{n}$ heredity is one of the outstanding features of the book.

The pointing out of a few small faults may halp the authors in the inevitable third edition. In fe $^{2}$ 